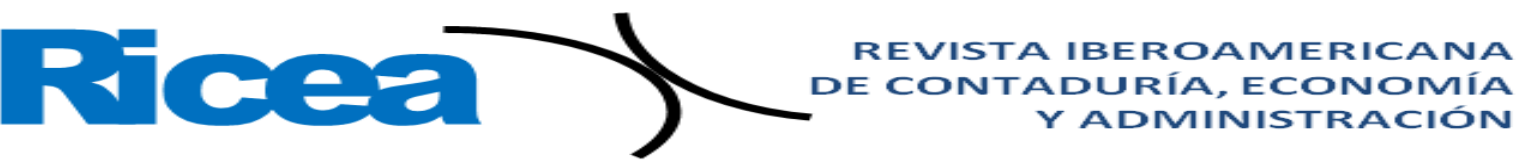

\title{
Predicción de quiebra empresarial en la auditoría financiera de pymes: un estudio descriptivo
}

\author{
Predicting business bankruptcy in the financial audit of SMEs: A descriptive \\ study
}

\section{Previsão de falência empresarial na auditoria financeira de PMEs: um estudo}

descritivo

Eva Lozano Montero

Universidad de Guanajuato, México

monteroe@ugto.mx

https://orcid.org/0000-0002-9721-3023

\section{Resumen}

La auditoría financiera es una herramienta enfocada en la confiabilidad de la gestión de los recursos, la cual es utilizada por las grandes empresas debido a que están obligadas a ello. Sin embargo, más que una herramienta que sirva para la detección de fraudes, la auditoría financiera favorece la eficiencia de la gestión empresarial, por lo que también debería ser aprovechada por las pymes como una estrategia de apoyo a la permanencia y a la competitividad en un mercado global. En esta investigación, por tanto, se ha procurado analizar cómo los modelos de predicción de quiebra empresarial en las pymes de la región Laja-Bajío generan beneficios en cuanto al eficiente control de los recursos y a la permanencia en el mercado. Para ello, se empleó un método cuantitativo, con un enfoque interpretativo y transversal, aplicado entre 2019 y 2020. Con base en la técnica de la encuesta aplicada a 305 empresas, y ocho entrevistas con empresas de la región Laja-Bajío de México, se detectó que temen la aplicación de la auditoría, y que están más familiarizadas con la auditoría fiscal, la cual confunden con la auditoría financiera. Asimismo, se observó una correlación directa entre la antigüedad de la empresa y la voluntad de acudir a la auditoría financiera. Igualmente, en cuanto al tamaño de la empresa, se apreció una correlación inversa, ya que a menor tamaño se interesan más por la herramienta mostrada. Cabe mencionar que al conocer los beneficios de la auditoría financiera y al diferenciarla de la auditoría fiscal, las empresas valoraron la aplicación de la herramienta, la cual consideraron 


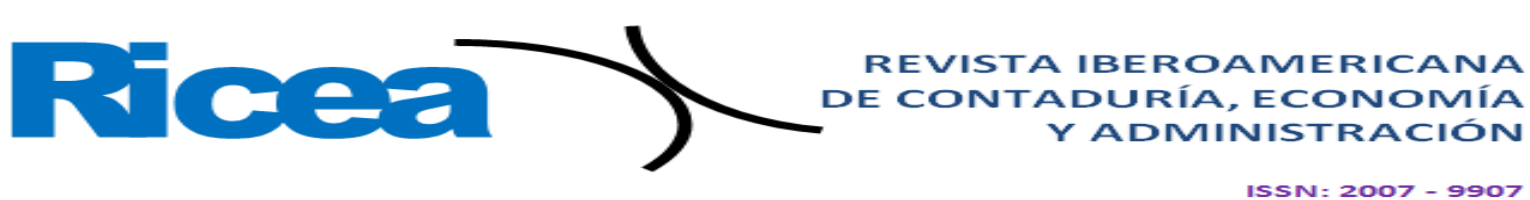

que garantizaría la permanencia y competitividad de las organizaciones. Además, se detectó que $84 \%$ de las empresas consultadas carecían de estados financieros, y al aplicar los modelos, $62.5 \%$ resultaron solventes. Se destaca, por tanto, la necesidad de fomentar una cultura financiera y profundizar en el estudio de los modelos de predicción de quiebra empresarial en pymes.

Palabras clave: auditoría financiera, estados financieros, pymes, quiebra empresarial.

\section{Abstract}

Financial auditing is a tool focused on the reliability of resource management, which is used by large companies because they are obliged to do so. However, more than a tool for fraud detection, financial auditing favors the efficiency of business management, so it should also be used by SMEs as a strategy to support their permanence and competitiveness in a global market. In this research, therefore, an attempt was made to analyze how business bankruptcy prediction models in SMEs in the Laja-Bajío region generate benefits in terms of efficient control of resources and permanence in the market. For this purpose, a quantitative method was used, with an interpretative and cross-sectional approach, applied between 2019 and 2020. Based on the survey technique applied to 305 companies, and eight interviews with companies in the LajaBajío region of Mexico, it was detected that they fear the application of auditing, and that they are more familiar with fiscal auditing, which they confuse with financial auditing. Likewise, a direct correlation was observed between the age of the company and the willingness to undergo a financial audit. Likewise, with regard to the size of the company, an inverse correlation was observed, since the smaller the company, the more interested it is in the tool shown. It is worth mentioning that by knowing the benefits of the financial audit and differentiating it from the tax audit, the companies valued the application of the tool, which they considered would guarantee the permanence and competitiveness of the organizations. In addition, it was detected that $84 \%$ of the companies consulted did not have financial statements, and when applying the models, $62.5 \%$ were solvent. Therefore, the need to promote a financial culture and to study the models for predicting business bankruptcy in SMEs is highlighted.

Keywords: financial audit, financial statements, SMEs, business bankruptcy. 


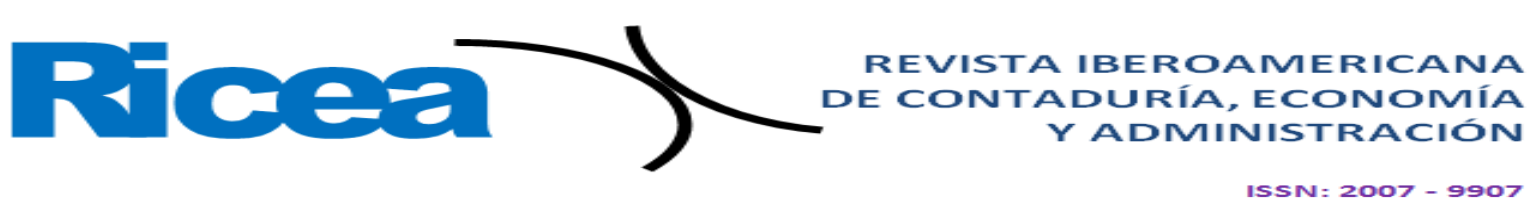

\section{Resumo}

A auditoria financeira é uma ferramenta voltada para a confiabilidade da gestão dos recursos, utilizada pelas grandes empresas porque são obrigadas a fazê-lo. No entanto, mais do que uma ferramenta que serve para detectar fraudes, a auditoria financeira favorece a eficiência da gestão empresarial, pelo que também deve ser utilizada pelas PME como estratégia de apoio à permanência e competitividade num mercado global. Nesta pesquisa, portanto, buscou-se analisar como os modelos de previsão de falências de empresas em PMEs da região de LajaBajío geram benefícios em termos de controle eficiente de recursos e permanência no mercado. Para isso, utilizou-se um método quantitativo, com abordagem interpretativa e transversal, aplicado entre 2019 e 2020. Com base na técnica de survey aplicada a 305 empresas, e em oito entrevistas com empresas da região de Laja-Bajío, no México, constatou-se que elas temem a aplicação da auditoria e estão mais familiarizados com a auditoria fiscal, que confundem com auditoria financeira. Da mesma forma, foi observada uma correlação direta entre a antiguidade da empresa e a disponibilidade para comparecer à auditoria financeira. Da mesma forma, em relação ao tamanho da empresa, observou-se uma correlação inversa, pois quanto menor o tamanho mais se interessam pela ferramenta apresentada. Vale ressaltar que ao conhecer os benefícios da auditoria financeira e diferenciá-la da auditoria tributária, as empresas valorizaram a aplicação da ferramenta, que consideraram garantir a perenidade e a competitividade das organizações. Além disso, detectou-se que $84 \%$ das empresas consultadas não apresentavam demonstrações financeiras e, na aplicação dos modelos, 62,5\% estavam solventes. Destaca-se, portanto, a necessidade de se promover uma cultura financeira e aprofundar o estudo dos modelos de previsão de falências de empresas em PMEs.

Palavras-chave: auditoria financeira, demonstrações financeiras, PMEs, falência de empresas.

Fecha Recepción: Mayo 2021 Fecha Aceptación: Diciembre 2021 


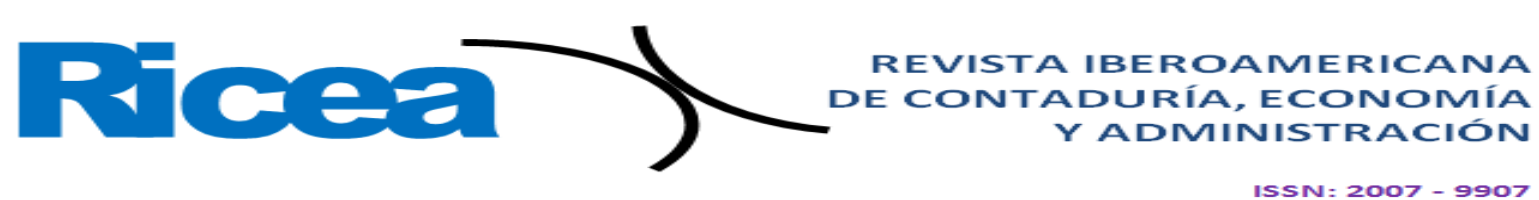

\section{Introducción}

Antes de la contingencia sanitaria provocada por la covid-19, el número de micro, pequeñas y medianas empresas (mipymes) en México era de 4.9 millones (97.3\% microempresas y $2.7 \%$ pequeñas y medianas empresas), las cuales contribuían con cerca de $52 \%$ del producto interno bruto (PIB) del país, y generaban alrededor de $72 \%$ del empleo formal. Sin embargo, según el Instituto Nacional de Estadística Geografía e Informática (Inegi) (2019) $65 \%$ de estas organizaciones quiebra antes de llegar a su primer lustro de vida debido, principalmente, a la falta de un financiamiento asequible y a la carencia de un proyecto viable. Aunado a esto, Lozano (2014) señala que los dueños de estas empresas generalmente deben desempeñar múltiples roles (como administradores, vendedores, técnicos, etc.), lo que puede impactar de manera negativa en la productividad de las pymes. De hecho, otros de los factores que contribuyen al fracaso de estas empresas son la carencia de liderazgo, la ineficiente gestión de los recursos, la carencia de un equipo de trabajo experimentado y de marketing estratégico, así como de recursos financieros (Lozano, 2013).

En el contexto global, se han efectuado estudios de riesgo empresarial relacionados con el sector agroindustrial, donde se señalan los factores de mayor amenaza para el sector, como el tipo de cambio, las inversiones y el tiempo de los activos que acuerdan (Kornyliuk; 2014; Stevanovski, et al., 2013). En este sentido, Restrepo, Díaz y Ocampo (2014) desarrollan un análisis de riesgo operacional para las pymes del sector químico en Colombia, donde se calculan las volatilidades de los principales ratios financieros capturando todos los indicadores de la industria, siendo el punto de referencia de evaluación de riesgos.

Estos modelos fueron creados para grandes empresas que cotizaban en la bolsa de valores, por lo que existen numerosos trabajos relacionados con la cuantificación del riesgo (Chernobai y Rachev, 2006; Chowdhry y Howe, 1999; Cruz, 2004; Frachot et al., 2003; Gillet et al., 2010; Marshall y Marshall, 2001). De hecho, también existen algunos estudios dedicados a las pymes, como el de Altman y Sabato (2007), quienes desarrollan un modelo de predicción de crisis financiera en pymes americanas. Asimismo, Behr y Güttler (2007) evalúan el riesgo crediticio en pymes alemanas, y Fantazzini y Figini (2008) miden la predicción del riesgo de quiebra mediante la comparación de modelos longitudinales.

Igualmente, Alzate Marín (2008) evalúa en Colombia el riesgo de quiebra en empresas del sector manufacturero de Santander, para lo cual usa el modelo Z de Altman, mientras que Khemais et al. (2016) realizan la predicción de quiebra en pymes tunecinas mediante modelos de Z Score de Altman, así como a través de modelos logísticos. 


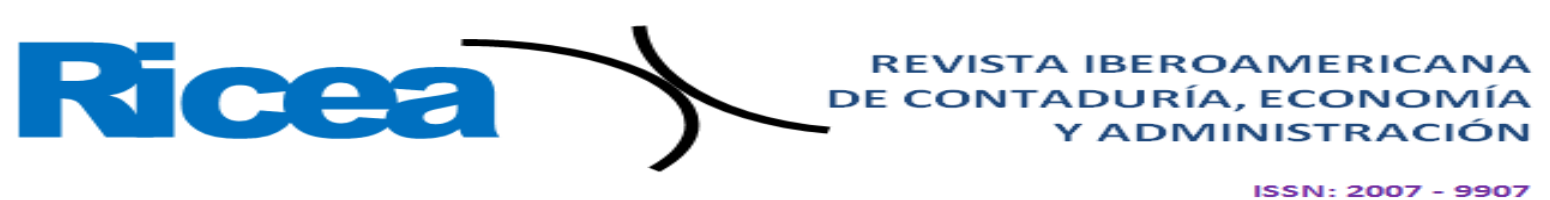

Sin embargo, y a pesar de indagaciones como las referidas, Celaya y López (2004) mencionan que existen pocos trabajos dedicados a la determinación y medición del riesgo inherente a la actividad de la empresa, particularmente de las pymes. Además, son mínimos los estudios estadísticos que permitan estimar modelos longitudinales para probar si existe un detrimento de la solvencia a lo largo del tiempo en este tipo de empresas del sector agroindustrial.

Por todo lo anterior, el objetivo de esta investigación fue analizar la manera en que a través de los modelos de predicción de quiebra empresarial, como parte de la auditoría financiera para las pymes de la región Laja-Bajío, se generan beneficios que coadyuvan al eficiente control de los recursos y a la permanencia en el mercado.

Para ello, se inició con la exploración de la percepción de las pymes de la región LajaBajío, del estado de Guanajuato, sobre los beneficios que genera la auditoría financiera, actividad que a través de los modelos de predicción de quiebra empresarial permite diseñar estrategias para evitar la quiebra y para fomentar su competitividad en su entorno.

Las preguntas de investigación formuladas fueron las siguientes:

- ¿Los modelos de predicción de quiebra empresarial coadyuvan a la permanencia y competitividad de las unidades económicas de la región Laja-Bajío?

- ¿Al conocer las pymes los beneficios de la auditoría financiera acudirían a ellas de manera voluntaria?

La hipótesis planteada fue la siguiente: las pymes de la región Laja-Bajío de Guanajuato tienen mayor posibilidad de permanecer en el mercado y de ser competitivas al acceder a la auditoría financiera a través de los modelos de predicción de quiebra empresarial.

\section{Auditoría financiera}

Para Sánchez (2015) este concepto se relaciona con el examen de estados financieros básicos presentados por la administración de una empresa o de cualquier persona jurídica para determinar si la información presentada se ajusta a las normas fijadas según las características de las transacciones.

Por su parte, las Normas de Auditoría Generalmente Aceptadas (NAGA) y las Normas Internacionales de Auditoría (NIA) establecen que el propósito principal de la auditoría financiera es emitir una opinión objetiva y profesional de la razonabilidad de los estados financieros preparados por personal administrativo, ya sea de una entidad pública o privada. 


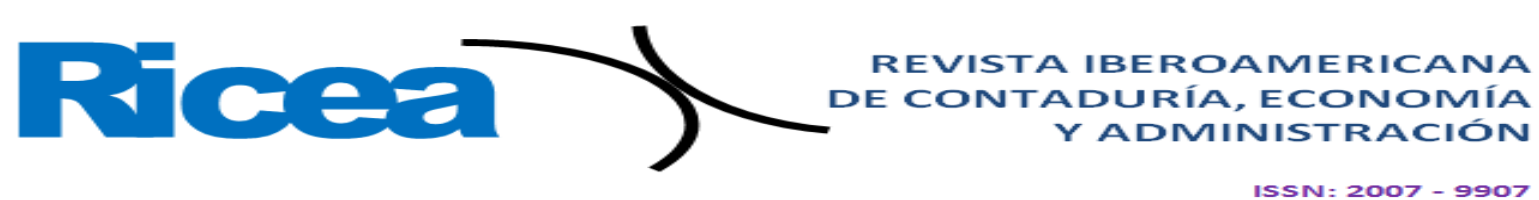

Las NAGA ofrecen principios, reglas y procedimientos fundamentales que deben considerar los auditores en su labor, mientras que las NIA son reglas, principios y procedimientos que se deben aplicar en las auditorías de los estados financieros, los cuales se deben interpretar según el contexto (Díaz, 2011).

Para llevar a cabo la auditoría financiera no importa el tamaño de una empresa, por lo que se debe incentivar a las pymes a que la acepten de forma voluntaria, lo cual brinda beneficios como los siguientes: a) credibilidad de la información financiera, b) mayor confianza para obtener financiación, c) aumento de la capacidad competitiva, d) valor agregado por la mejora en sus procesos internos, e) garantiza la permanencia, f) crea una cultura financiera estable y g) contribuye a la disminución de actividades ilegales y a los fraudes dentro de la empresa.

Por otra parte, es importante considerar que la auditoría financiera es diferente a la auditoría fiscal, aunque se puede afirmar que esta se encuentra dentro de aquella, ya que la última se centra en verificar si la empresa ha cumplido con sus obligaciones fiscales, enfocándose en los resultados contables, por lo que es externa a la empresa. En cambio, la auditoría financiera es un proceso interno y voluntario que evalúa las operaciones económicas con el objetivo de que estén plasmadas correctamente en la información financiera, lo que sirve para proponer estrategias que contribuyan al eficiente control de los recursos.

De hecho, autores como Hellman (2006) y Sánchez (2015) mencionan que las empresas esperan algún aporte adicional de la auditoría debido a que pagan un alto costo por ello, de ahí que exijan mejores servicios a los auditores, quienes deben señalar estrategias orientadas a la prevención de riesgos. Además, Johnson y Lys (1990) indican que el precio de la auditoría es un determinante para que las empresas decidan contratar el servicio de forma independiente. Según Collis, Jarvis y Skerratt (2004), Collis (2010) y Chung y Narasimhan (2001), la auditoría brinda beneficios superiores a su costo, por lo que los empresarios suelen quedar satisfechos. En pocas palabras, los procedimientos de auditoría pueden ayudar a regular a las empresas (Collis, 2008; Knechel et al., 2008).

Las auditorías, en general, son muy necesarias no solo para cumplir con las directrices legales, sino también para añadir valor a las empresas disminuyendo el costo de asimetría de la información y el riesgo moral, los cuales son detectados por los procedimientos de auditoría.

En México, se exime la obligación de la auditoría fiscal a un gran número de empresas, aunque no sucede lo mismo con la auditoría financiera. Las empresas que no estaban obligadas a ser auditadas acudían a este servicio con la finalidad de prevenir posibles multas o faltas administrativas, lo que incrementaba notablemente la demanda de auditorías; sin embargo, se ha restado interés a la contratación de este servicio, ya que — de acuerdo con lo establecido en 


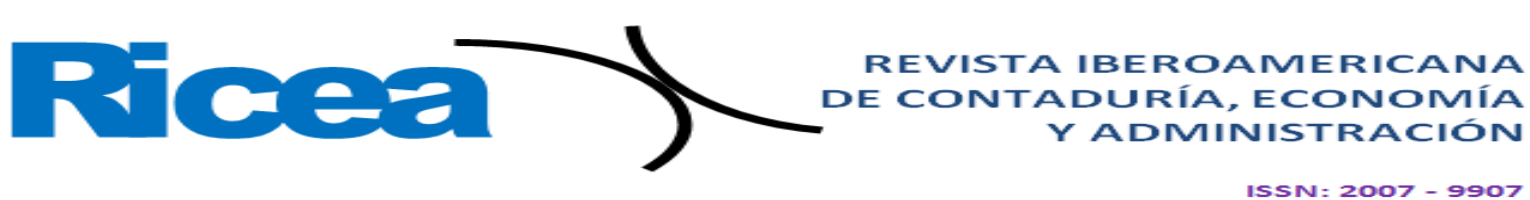

el artículo 32-A del Código Fiscal de la Federación (CFF) (2021) — se dispone de manera opcional la posibilidad de ser auditados, en los términos del artículo 52 del CFF, a excepción de las entidades paraestatales de la administración pública federal.

Las partes interesadas de una auditoría financiera son principalmente los dueños, así como los bancos y las autoridades fiscales, las cuales procuran el cumplimiento de las Normas de Información Financiera (NIF) (2019). Este procedimiento es útil para comprobar si las cifras de los estados financieros reflejan la imagen de una empresa de acuerdo con el marco normativo aplicado en ese momento en determinado país.

Es conocido que existen firmas que están obligadas a ser auditadas y a publicar sus estados financieros dictaminados, ya que deben cumplir con las Normas Internacionales de Auditoría (NIA) —emitidas por la International Federation of Accountants (IFAC)—, las cuales en México son aceptadas tanto por la Comisión Nacional Bancaria y de Valores (CNBV) como por la Secretaría de Hacienda y Crédito Público.

Ahora bien, cabe destacar que la auditoría de estados financieros, así como la auditoría en general, presenta grandes desafíos, ya que los clientes no suelen quedar plenamente satisfechos, de ahí que demanden mejores servicios de los auditores independientes, en especial en lo concerniente a la prevención de riesgos (Sánchez, 2015). Aunado a esto, García y Vico (2003) y Herreros (22 de febrero de 2015) explican que la sociedad suele percibir que los auditores han estado actuando con extrema libertad y se han convertido en defensores de los intereses de los directivos de las empresas que auditan.

Por eso, y ya que el propósito de las auditorías es contribuir al eficiente control de los recursos para disminuir los riesgos empresariales, en esta investigación se proponen métodos de predicción de quiebra como herramientas dentro de la auditoría financiera para evitar que ello suceda, principalmente en pymes.

\section{Competitividad}

Para permanecer en el mercado las unidades económicas deben mostrar que son competitivas, entendido esto último como la capacidad de generar satisfacción en los consumidores debido a que ofrecen un valor agregado en sus bienes o servicios. Una empresa puede ser competitiva según su capacidad de exportar productos y competir en el mercado internacional (Morales y Pech, 2000), pero también puede serlo cuando puede diferenciarse de sus competidores, lo que impulsa la preferencia por parte de los consumidores.

En el caso de México, la Ley para el Desarrollo de la Competitividad de la Micro, Pequeña y Mediana Empresa define competitividad del siguiente modo: 
La fórmula original es:

$\mathrm{Z}=$ Punto de interrupción.

$\mathrm{Vn}=$ Coeficiente discriminante.

$\mathrm{Xn}=$ Ratios financieros, de donde:

$\mathrm{Z}=$ Indicador global (índice general).

$\mathrm{X} 1$ = Capital de trabajo/activos totales.

$\mathrm{X} 2$ = Total de utilidades retenidas/activo total.

X3 = EBIT/activo total.

$\mathrm{X} 4$ = Patrimonio neto/valor contable del pasivo total.

X5 = Ventas/activo total (Altman, 1968).

Posteriormente, Altman desarrolla otros modelos para negocios, con actividades distintas a las manufactureras y que no cotizaban en bolsa, que se implementaron en 2006 aplicables a todos los sectores.

$$
\mathrm{Z}_{2}=6.56 \mathrm{X}_{1}+3.26 \mathrm{X}_{2}+6.72 \mathrm{X}_{3}+1.05 \mathrm{X}_{4}
$$

Este modelo es el que se propone aplicar en las pymes, y los puntajes obtenidos se interpretan de acuerdo con los criterios establecidos por Altman, donde dependiendo del resultado de $\mathrm{Z}$, se puede predecir si la empresa es segura o tiene una gran probabilidad de fracaso dentro de los siguientes dos años de operación (tabla 1).

Tabla 1. Interpretación de puntajes de Z Altman

\begin{tabular}{|l|l|}
\hline Puntaje & Interpretación \\
\hline$Z$ arriba 3.0 & La empresa se considera como "segura". \\
\hline$Z$ entre 2.7 y 2.99 & "En alerta". Precaución en la empresa. \\
\hline$Z$ entre 1.8 y 2.7 & $\begin{array}{l}\text { Posibilidad de quiera en los siguientes dos años de } \\
\text { operación. }\end{array}$ \\
\hline$Z$ por debajo de 1.8 & Alta probabilidad de fracaso financiero. \\
\hline
\end{tabular}

Fuente: Altman (1968)

El puntaje Z Altman clasifica a las empresas en solventes e insolventes: si excede un valor de corte, la compañía se considera solvente; de lo contrario, se indica un riesgo significativo en un futuro cercado, con una precisión de entre $80 \%$ y $90 \%$ (Bernal, 2011).

\section{Modelo Springate}

Gordon Springate (1978) desarrolló un modelo con una precisión de $92.5 \%$, considerando los procedimientos de Altman y trabajando con 19 razones financieras que ayudan a detectar negocios con un futuro solvente y otros con tendencias a problemas de solvencia. El modelo de Springate es el siguiente: 


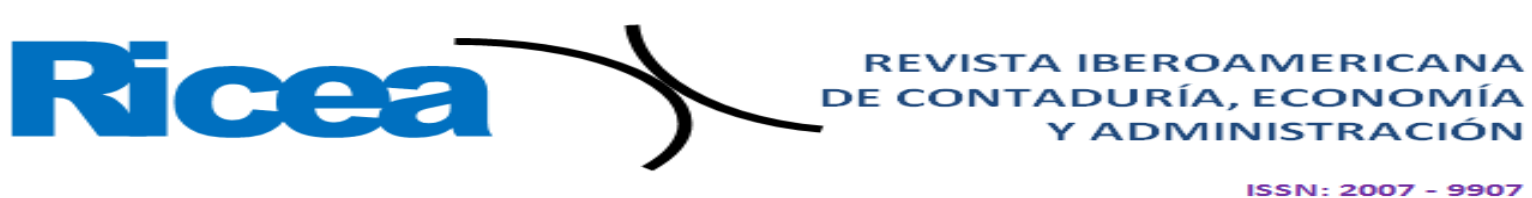

$$
Z=1.03 A+3.07 B+0.66 C+0.40 D
$$

donde

$\mathrm{A}=$ Capital de trabajo/activos totales.

$\mathrm{B}=$ Ingresos netos antes de intereses e impuestos/activos totales.

$\mathrm{C}=$ Ingresos netos antes de impuestos/pasivos corrientes.

$\mathrm{D}=$ Ventas/activos totales

Criterio por considerar: Cuando $\mathrm{Z}<0.862$, la empresa puede considerarse insolvente.

\section{Modelo Fulmer}

El modelo Fulmer fue desarrollado en 1984 y consideró nueve razones financieras, con $98 \%$ de precisión. Este es valorado como el más completo debido a que considera cuarenta razones financieras aplicadas a una muestra de 60 empresas. La ecuación es la siguiente:

$$
\mathrm{H}=5.528 \mathrm{X}_{1}+0.212 \mathrm{X}_{2}+0.073 \mathrm{X}_{3}+1.270 \mathrm{X}_{4}+0.120 \mathrm{X}_{5}+2.335 \mathrm{X}_{6}+0.575 \mathrm{X}_{7}+1.083 \mathrm{X}_{8}+0.894 \mathrm{X}_{9}-6.075
$$

donde

$\mathrm{X} 1=$ Utilidades retenidas/activos totales.

$\mathrm{X} 2=$ Ventas/activos totales

X3 = Utilidades antes de impuestos/capital contable.

$\mathrm{X} 4$ = Flujo de caja/pasivo total.

$\mathrm{X} 5$ = Pasivo total/activo total.

X6 = Pasivos corrientes/activos totales.

$\mathrm{X} 7=$ Total de activos tangibles.

$\mathrm{X} 8$ = Capital de trabajo/pasivo total.

X9 = Log utilidad operativa/gastos financieros.

Una vez obtenido el resultado, se debe considerar que cuando $\mathrm{H}<0$, la compañía puede ser “insolvente" en un futuro de más de un año (Fulmer et al., 1984).

\section{Modelo CA-SCORE}

Jean Legault (1987), de la Universidad de Quebec, desarrolló el modelo CA-Score, uno de los más recomendados por analistas financieros en Canadá, aunque tiene un nivel de confianza de $83 \%$ en promedio, además de que solo es aplicable en compañías manufactureras (Jiménez, 2013). Este modelo se desarrolló utilizando treinta razones financieras en una muestra de 173 empresas manufactureras, mediante la siguiente fórmula:

Puntuación CA-SCORE $=4.5913 \mathrm{X}_{1}+4.5080 \mathrm{X}_{2}+0.3936 \mathrm{X}_{3}-2.7616$, donde:

$\mathrm{X}_{1}=$ Capital contable/activos totales. 


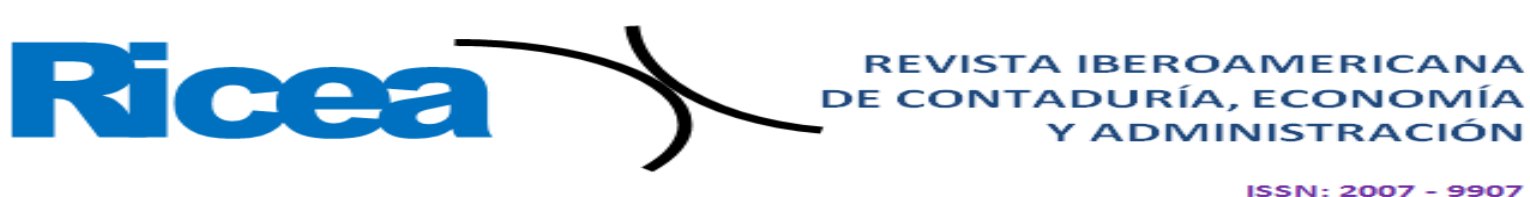

$\mathrm{X}_{2}=($ Beneficio antes de impuestos y partidas extraordinarias + gastos financieros $) /$ activos totales.

$\mathrm{X}_{3}=$ Ventas/activos totales.

Cuando CA-SCORE < - 0.3, es muy probable que la empresa se considere insolvente.

En la tabla 2 se observa un comparativo de los modelos con sus porcentajes de precisión, su aplicabilidad con el tipo de empresa y algunas observaciones. Se puede deducir que el modelo que no sería aconsejable para aplicar a las pymes del presente trabajo es el CA-Score, empleado en empresas manufactureras.

Tabla 2. Comparativa de los modelos de predicción de insolvencia financiera

\begin{tabular}{|l|l|l|l|}
\hline Modelo & Precisión & Dirigido a & Observaciones \\
\hline $\begin{array}{l}\text { Z Score de } \\
\text { Altman }\end{array}$ & $80 \%$ y 90 \% & $\begin{array}{l}\text { Manufactura } \\
\text { Negocios de diversas } \\
\text { actividades }\end{array}$ & $\begin{array}{l}\text { Aplicable a empresas de fabricación } \\
\text { y cualquier tipo de negocio, ya sea } \\
\text { con capital abierto o cerrado. }\end{array}$ \\
\hline $\begin{array}{l}\text { Gordon } \\
\text { Springate }\end{array}$ & $92.5 \%$ & $\begin{array}{l}\text { Negocios de diversas } \\
\text { actividades }\end{array}$ & $\begin{array}{l}\text { Aplicable a cualquier tipo de } \\
\text { negocio. }\end{array}$ \\
\hline Fulmer & $81 \%$ y $98 \%$ & $\begin{array}{l}\text { Negocios de diversas } \\
\text { actividades }\end{array}$ & $\begin{array}{l}\text { Aplicable a cualquier tipo de } \\
\text { negocio. }\end{array}$ \\
\hline CA-Score & $83 \%$ & Manufactura & $\begin{array}{l}\text { Solo aplicable a empresas de } \\
\text { manufactura. }\end{array}$ \\
\hline
\end{tabular}

Fuente: Elaboración propia

Es importante aclarar que para que algún modelo sea eficiente, se recomienda usarlo en pymes que tengan al menos dos años de operación. En este sentido, también vale señalar que antes de la contingencia sanitaria, $80 \%$ de las mipymes cerraban debido a la falta de previsión financiera y administrativa (Organización Internacional del Trabajo, 2020). Por eso, ahora se debe poner énfasis en aquellas que luchan por sobrevivir.

En el caso de México, de las 4.9 millones de unidades económicas que existían en diciembre de 2020, cerraron más de un millón, de acuerdo con la Encuesta sobre el Impacto Generado por Covid-19 en las Empresas (ECOVID-IE) y el Estudio sobre la Demografía de los Negocios 2020 (EDN). Sin embargo, también se reconoce que han nacido más de 600000 negocios, por lo que se estima que en el país existen 4.5 millones de unidades económicas (Meza, 2 de diciembre de 2020).

Existen estudios de predicción de quiebra que han empleado datos transaccionales y variables basadas en la red de pago (Kou et al., 2021), así como el modelo propuesto por Tobback, Bellotti, Moeyersoms, Stankova y Martens (2019), que complementa las cifras financieras de baja dimensión con datos de alta dimensión sobre directores y gerentes de la empresa, en donde - a través de una red entre pymes - dos empresas están relacionadas si comparten un director o un gerente de alto nivel; mientras que Gordini (2014) compara el 


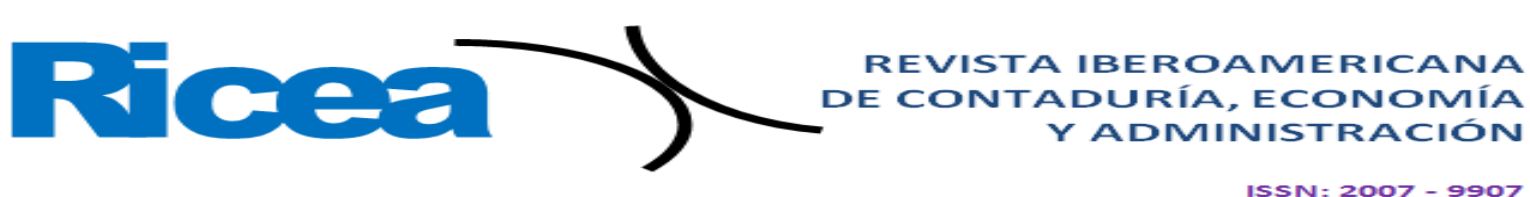

potencial de los algoritmos genéticos (GA) con los de regresión logística (LR) y el modelo de vectores de soporte (SVM). Su conclusión es que los GA son más eficaces para evaluar la probabilidad de quiebra de las pymes.

\section{Metodología}

Para comprobar la hipótesis planteada se analizó el nivel de insolvencia utilizando los modelos de Z Score de Altman, Springate, Fulmer y CA-SCORE, que miden el riesgo de quiebra y muestran los beneficios que generan a las pymes de la región Laja-Bajío.

Para conocer la percepción de las pymes, así como su participación de manera voluntaria en esta investigación, se utilizó la técnica de la encuesta, con apoyo del software SPSS, mediante un enfoque interpretativo y transversal.

\section{Población de estudio y muestra}

El interés se enfocó en analizar las pymes de la región Laja-Bajío, que comprende los municipios de Celaya, Apaseo El Alto, Apaseo El Grande, Salvatierra, Comonfort, Jaral del Progreso y Tarimoro. En el estado de Guanajuato existen 222969 empresas, de las cuales se muestra en la tabla 3 el número por municipio que conforman la región Laja-Bajío (Directorio Empresarial, 2019). De todas, $2.7 \%$ son pymes (Inegi, 2019).

Tabla 3. Número de empresas por municipio de la región Laja-Bajío

\begin{tabular}{|l|l|l|l|}
\hline Municipio & $\begin{array}{l}\text { Unidades } \\
\text { económicas }\end{array}$ & $\begin{array}{l}\text { Porcentaje de } \\
\text { participación }\end{array}$ & $\begin{array}{l}\text { Ponderación de } \\
\text { empresas }\end{array}$ \\
\hline Celaya & 33306 & 60 & 127 \\
\hline Apaseo El Alto & 3834 & 6.8 & 14 \\
\hline Apaseo El Grande & 3901 & 7.0 & 15 \\
\hline Salvatierra & 6511 & 11.7 & 24 \\
\hline Comonfort & 3856 & 6.9 & 15 \\
\hline Jaral del Progreso & 2424 & 4.3 & 9 \\
\hline Tarimoro & 1861 & 3.3 & 7 \\
\hline Total & 55393 & 100 & 211 \\
\hline Pymes 2.7 \% & 1496 & & \\
\hline
\end{tabular}

Fuente: Elaboración propia con información del Inegi (2019) y el Directorio Empresarial (2019)

Considerando una población finita de 1496 empresas, se calculó la muestra con un nivel de confianza de $95 \%$ y un margen de error de 5\%, utilizando la siguiente fórmula: 

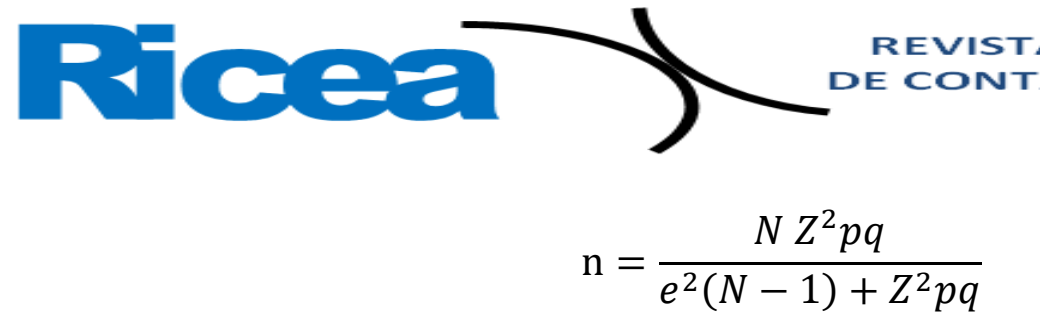

La muestra fue de 211 unidades económicas a las que se debería aplicar la encuesta; sin embargo, se usaron 305 gracias a la participación activa de los municipios de Celaya y Salvatierra. Además, se destaca que las empresas participantes fueron pymes (pues contaban con entre 11 y 250 empleados), con permanencia en el mercado de dos años como mínimo. Estas realizaban diversas actividades comerciales y de manufactura, y habían pasado por el periodo de "sobrevivencia".

A estas organizaciones se les aplicó la encuesta referente a la auditoría financiera, que se combina con los métodos de predicción de quiebra empresarial como una forma para proponer alternativas de solución a sus realidades específicas (al final del manuscrito se anexa el cuestionario).

Esta investigación se realizó entre 2019 y 2020, ya que — debido a la pandemia que todavía se está viviendo - las unidades económicas a las que se les envió la información vía correo electrónico tardaban en contestar. De hecho, otras a las que se acudió de forma personal estaban cerradas o abrían por pocas horas, lo que prolongó la investigación.

\section{Resultados}

El análisis permitió determinar las variables de mayor relevancia para esta investigación, así como su significancia y correlación entre ellas. Cabe señalar que este estudio se enfocó solo en las pymes ( $\sin$ considerar a las microempresas), ya que son las que presentan mayor probabilidad de llevar registros contables y estados financieros, que son indispensables para la auditoría financiera y para el análisis de insolvencia.

Respecto a la percepción que tienen las pymes sobre los beneficios que proporciona la auditoría financiera y para comprobar la confiabilidad del instrumento documental, se utilizó la prueba estadística de coeficiente de alfa de Cronbach para los ítems cualitativos ordinales, y el coeficiente de Kuder Richardson para los ítems cualitativos nominales. Los resultados obtenidos fueron 0.92 y 0.87 , respectivamente, los cuales son interpretados con una confiabilidad alta. Para este primer análisis se utilizó el software SPSS y para el segundo se empleó Excel.

En la tabla 4 se presenta la relación de las variables utilizadas en esta investigación con sus correspondientes ítems del instrumento documental. 


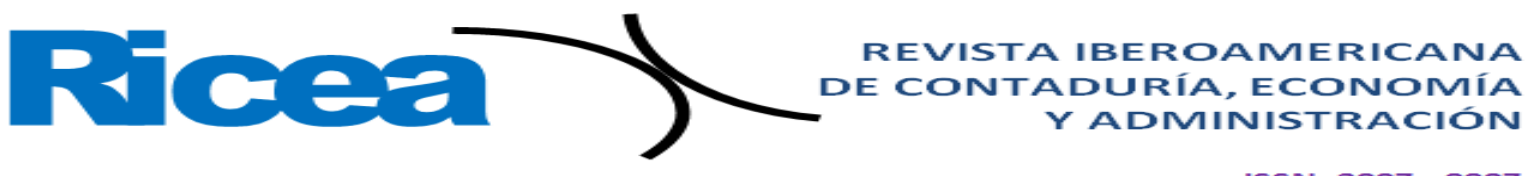

Tabla 4. Relación de las variables de estudio con el instrumento documental

\begin{tabular}{|l|l|l|}
\hline Variable & Ítem \\
\hline Dependiente & $\begin{array}{l}\text { Auditoría financiera- } \\
\text { modelos de predicción de } \\
\text { quiebra }\end{array}$ & 3 \\
\hline \multirow{4}{*}{ Independiente } & Antigüedad de la empresa & \\
\cline { 2 - 3 } & $\begin{array}{l}\text { Grado de estudios del } \\
\text { dueño }\end{array}$ & \\
\cline { 2 - 3 } & Tamaño de la empresa & \\
\hline
\end{tabular}

Fuente: Elaboración propia

Mediante el uso de estadística descriptiva sobre elementos de naturaleza ordinal, en la tabla 5 se muestran la media y la desviación estándar. La edad promedio fue de 3.1 a 10 años y el tamaño promedio de las unidades económicas fue de 11 a 50 empleados, lo que significa que son pymes (Franco-Ángel y Urbano, 2016). Sin embargo, debido a la contingencia sanitaria ocasionada por la covid-19, algunas empresas manifestaron que de no presentarse una apertura en los negocios, se verían obligados a despedir a algunos empleados.

Tabla 5. Media y desviación estándar de los ítems

\begin{tabular}{|l|l|l|}
\hline Estadística descriptiva & Media & $\begin{array}{l}\text { Desviación } \\
\text { estándar }\end{array}$ \\
\hline 1. Antigüedad de la empresa & 1.95 & .805 \\
\hline 2. Tamaño de la empresa (por el número de empleados) & 1.86 & .793 \\
\hline 5. Grado de estudio del dueño & 3.43 & .507 \\
\hline
\end{tabular}

Fuente: Elaboración propia

A continuación, se muestra una comparación entre la variable dependiente auditoría financiera-modelos de predicción de quiebra con algunas de las variables independientes de naturaleza ordinal a través de un análisis no paramétrico empleando la prueba estadística de Wilconxon.

La primera comparación mide la disposición para participar en la auditoría financiera con la antigüedad de la empresa, lo que da como resultado el estadístico de prueba, cuyo valor de significancia asintótica es menor a 0.05 ; por tanto, se concluye que la disposición para la auditoría financiera es diferente entre la antigüedad de la organización, por lo que las empresas con mayor antigüedad son las que muestran mayor disposición para participar en la aplicación de la auditoría financiera (tabla 6). 


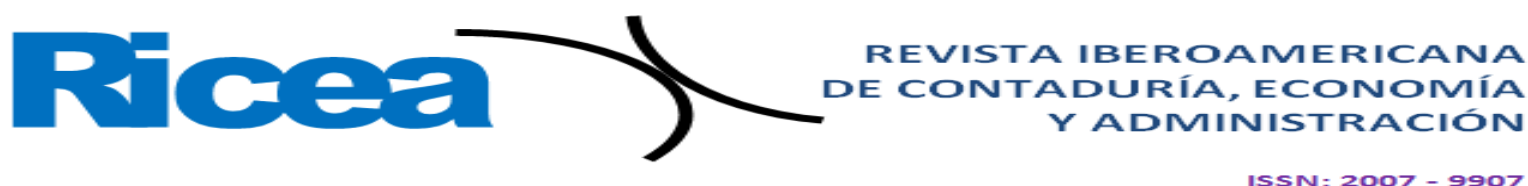

Tabla 6. Estadísticos de prueba ${ }^{a}$ Auditoría financiera y antigüedad de la empresa

\begin{tabular}{|l|l|}
\hline & $\begin{array}{l}\text { 1. La antigüedad de la empresa es: }-9 . \text { ¿Estaría dispuesto(a) a } \\
\text { acceder de manera voluntaria a la misma? }\end{array}$ \\
\hline$Z$ & $-4.064^{\mathrm{b}}$ \\
\hline $\begin{array}{l}\text { Sig. asintótica } \\
\text { (bilateral) }\end{array}$ & .000 \\
\hline
\end{tabular}

a. Prueba de Wilcoxon de los rangos con signo.

b. Se basa en rangos negativos.

Fuente: Elaboración propia

La segunda comparación fue probar la auditoría financiera, específicamente si era igual o diferente para los diversos tamaños de la empresa, lo que arrojó un estadístico de prueba de $Z=-3.666$, por lo que se concluye que la auditoría financiera se percibe de manera diferente dependiendo del tamaño de la empresa. Se destaca que a menor tamaño de la empresa estarían más dispuestos a una auditoría financiera, en este caso en específico los modelos de predicción de quiebra empresarial (figura 1).

Figura 1. Disposición para la auditoría financiera relacionada con el tamaño de la empresa

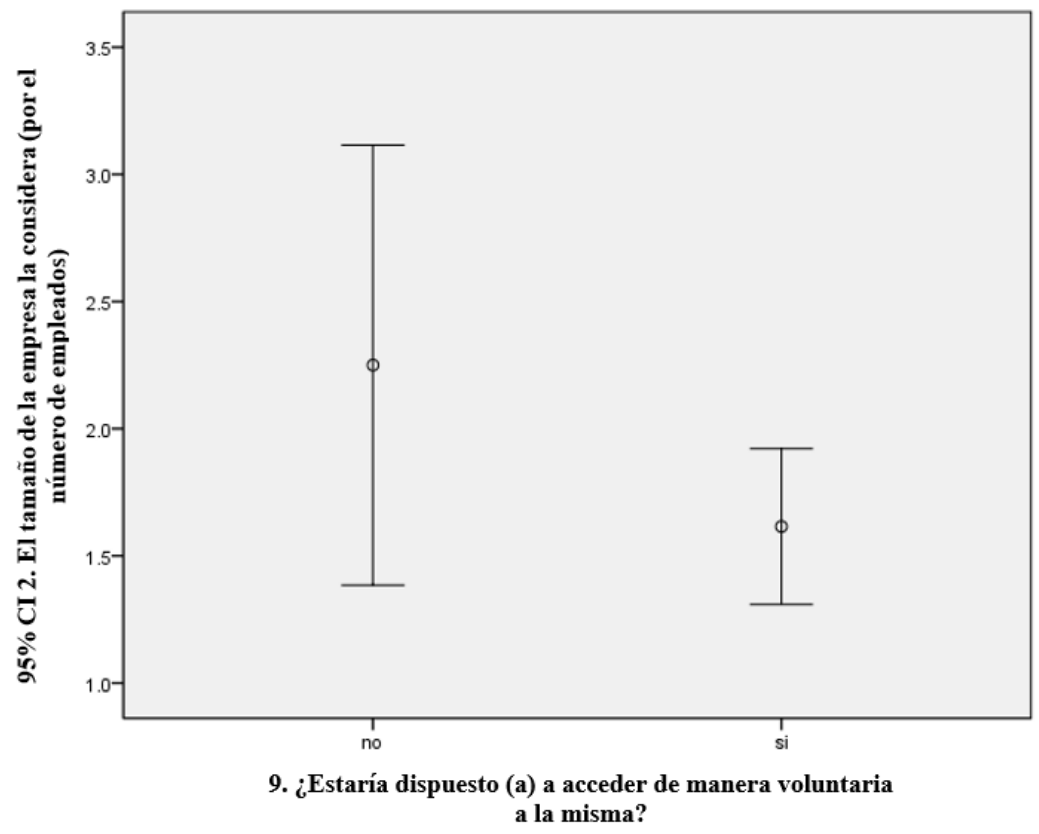

Fuente: Elaboración propia

Los resultados del estudio de estadística descriptiva para las variables de naturaleza cualitativa nominal indican que $90.48 \%$ de las pymes participantes en la investigación estaban constituidas como personas morales, lo que favorece la permanencia de las empresas, ya que la responsabilidad no recae en una sola persona y genera confianza con terceros. Asimismo, 57.8 $\%$ son consideradas como empresas familiares, lo que indica que es una forma común de constitución. Además, $64 \%$ no ha escuchado hablar de la auditoría financiera, aunque $86 \%$ opina que las auditorías son caras. Igualmente, la confunden con la auditoría fiscal, ya que al 


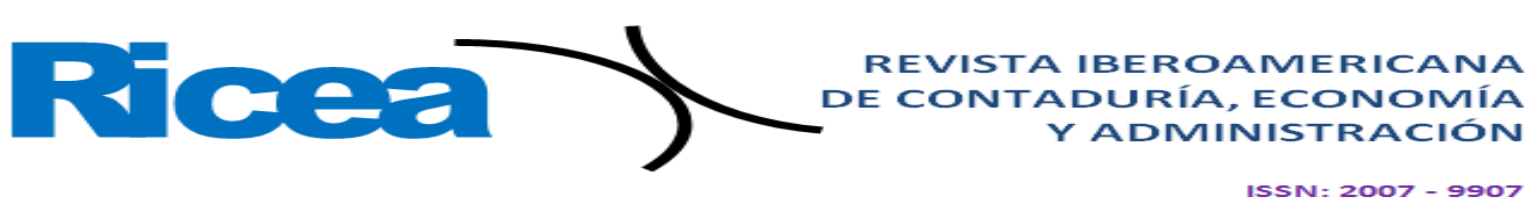

mencionar el término auditoría, $60 \%$ de los dueños mostraron temor a ella porque la asocian con la detección de fraudes. Sin embargo, es confortable observar que una vez explicado el proceso y los beneficios de la auditoría financiera, $78 \%$ estaban dispuestos a participar en el proyecto. Por último, a $89 \%$ de las empresas nunca se les ha practicado una auditoría.

\section{Modelos de predicción de quiebra empresarial}

De las 305 unidades económicas a las que se les aplicó la encuesta, 238 accedieron a participar de manera voluntaria en la aplicación de los modelos de predicción de quiebra, por lo que se les solicitaron los estados financieros actualizados, es decir, el balance general (estado de posición financiera) y el estado de resultados (estado de pérdidas y ganancias). Al respecto, $84 \%$ carecía de los estados financieros. Por eso, solamente se consideraron 38 empresas (16 $\%)$, aunque una gran porción de estas no tenían los estados financieros actualizados para la fecha de la solicitud o estaban incompletos, de modo que quedaron solo ocho unidades económicas (3.4\%), que proporcionaron la información por el ejercicio 2019 y disponibles para la aplicación de los modelos.

Esta situación es muy preocupante. En México es muy común que las empresas cumplan con sus obligaciones fiscales, pero no elaboren estados financieros, los cuales solo son creados cuando son requeridos para solicitar un crédito o para tener acceso a una convocatoria.

Las ocho pymes que pudieron participar tenían más de tres años de operatividad en el mercado, con diversas cantidades de trabajadores y actividades empresariales diferentes. Por eso, se procedió a realizar una entrevista previa a la aplicación de los modelos de predicción de quiebra empresarial con la finalidad de conocerlas y generar confianza. Así se observó que los principales factores que afectaban al desarrollo empresarial se centraban en la administración de sus activos, en la capacidad de planeación estratégica, en el financiamiento asequible para ampliar o mejorar su negocio, y en la administración de pasivos y reducción de costos (figura 2). 


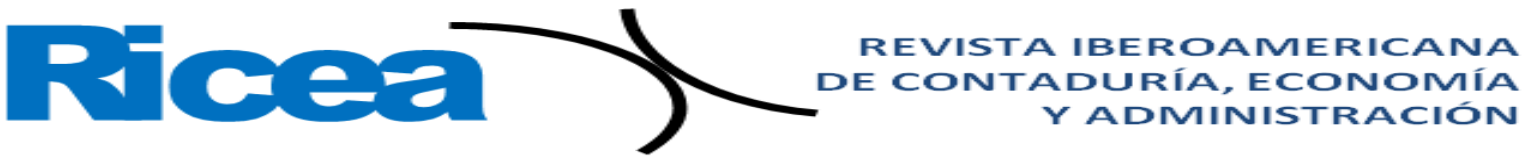

Estos indicadores obtenidos en la primera intervención son de gran utilidad para conjuntarlos con los resultados recabados en la aplicación de los modelos de predicción de quiebra empresarial, ya que contribuyen a prevenir e implementar estrategias que prevengan la quiebra empresarial.

A continuación, se dan a conocer los hallazgos de la aplicación de los modelos de predicción de quiebra empresarial en una pyme. Por razones de confidencialidad se omite el nombre de la entidad económica, y en la tabla 7, se muestra información para el séptimo y octavo año de operación, que corresponde a los ejercicios 2018 y 2019.

\section{Modelo Z-Score de Altman}

Se usó el modelo Z2 Score, apto para las compañías genéricas y aquellas con capital cerrado.

$\mathrm{Z} 2=6.56 \mathrm{X}_{1}+3.26 \mathrm{X}_{2}+6.72 \mathrm{X}_{3}+1.05 \mathrm{X}_{4}$

donde

$\mathrm{X}_{1}=$ Capital de trabajo/activos totales.

$\mathrm{X}_{2}=$ Ganancias acumuladas/activos totales.

$\mathrm{X}_{3}=$ EBIT/activos totales.

$\mathrm{X}_{4}=$ Capital contable/valor contable de la deuda total.

Tabla 7. Información contable-financiera de una PyME

\begin{tabular}{|l|c|l|}
\hline Concepto & Octavo año & Séptimo año \\
\hline Activos corrientes & $\$ 21793.40$ & $\$ 20852.00$ \\
\hline Activos totales & 62548.00 & 53498.09 \\
\hline Pasivos corrientes & 5178.00 & 5655.50 \\
\hline Pasivos totales & 9080.00 & 10431.75 \\
\hline Capital de trabajo & 16615.40 & 15196.50 \\
\hline Ganancias retenidas & 11148.00 & 8238.00 \\
\hline EBIT & 48820.00 & 41328.34 \\
\hline $\begin{array}{l}\text { Utilidad antes de } \\
\text { Impuestos }\end{array}$ & 30640.00 & 23148.34 \\
\hline Ventas & 114060.00 & 96434.00 \\
\hline Capital contable & 53468.00 & 43066.34 \\
\hline EBITDA & 58680.00 & 53181.34 \\
\hline Total activo fijo & 40754.60 & 32646.09 \\
\hline Gastos financieros & 18180.00 & 18180.00 \\
\hline Capital contable & 53468.00 & 43066.34 \\
\hline
\end{tabular}

Fuente: Elaboración propia 
Resultados: Altman Z-Score, cálculo séptimo año, $Z=11.8915542$ y octavo año $\mathrm{Z}=13.7517192$, los cuales indican que la compañía se encuentra en un área sólida y confiable en ambos años de operación, ya que el parámetro es z > 3.0, por lo que se puede afirmar que en los siguientes dos años no presentará problemas de insolvencia.

\section{Modelo Gordon Springate}

$\mathrm{Z}=1.03 \mathrm{~A}+3.07 \mathrm{~B}+0.66 \mathrm{C}+0.40 \mathrm{D}$

Séptimo año $Z=6.08666$; octavo año $Z=7.30468$

De acuerdo con el parámetro establecido, la compañía obtiene una puntuación más alta que $Z>0.862$ en ambos años, lo que confirma lo establecido por el método de Altman, como solvente por los siguientes dos años.

\section{Aplicación del modelo Fulmer}

$\mathrm{H}=5.528 \mathrm{X} 1+0.212 \mathrm{X} 2+0.073 \mathrm{X} 3+1.270 \mathrm{X} 4+0.120 \times 5+2.335 \mathrm{X} 6+0.575 \mathrm{X} 7+1.083 \mathrm{X} 8+0.894 \mathrm{Log}$ X9-6.075

Séptimo año $H=18771.0861$; octavo año $H=23434.4746$, por lo que se observa que $\mathrm{H}>0$, de modo que se considera solvente por dos años más, de acuerdo con este modelo.

Se aclara que el modelo CA-Score no se aplicó debido a que la empresa no se dedica a procesos de manufactura.

Por otra parte, así como en esta empresa se pudo predecir la solvencia financiera de hasta por dos años, en otras más se observó que tres serían insolventes, de las cuales se procedió a buscar estrategias para disminuir el riesgo de quiebra empresarial (tabla 8). Cabe señalar que el ejercicio contable de los estados financieros proporcionados por las unidades económicas correspondió al año 2019. 


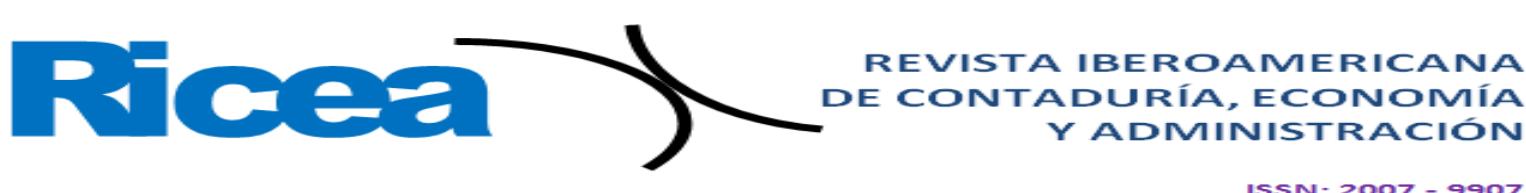

Tabla 8. Modelos de predicción de quiebra empresarial en las pymes

\begin{tabular}{|l|l|l|l|l|l|}
\hline Nombre/modelo & Z Score Altman & Springate & Fulmer & CA-Score & \multicolumn{1}{|c|}{ Estado } \\
\hline Empresa A & 1.52 & 0.345 & 0.0023 & N/A & Insolvente \\
\hline Empresa B & 1.61 & 0.546 & 0.035 & N/A & Insolvente \\
\hline Empresa C & 2.45 & 0.658 & 0.059 & N/A & Insolvente \\
\hline Empresa D & 3.84 & 2.11 & 4861.45 & N/A & Solvente \\
\hline Empresa E & 5.36 & 3.65 & 5631.13 & 0.002 & Solvente \\
\hline Empresa F & 2.91 & 1.87 & 2356.78 & N/A & Solvente \\
\hline Empresa G & 8.19 & 5.461 & 11315.42 & 1.89 & Solvente \\
\hline Empresa H & 13.75 & 7.304 & 23434.47 & N/A & Solvente \\
\hline
\end{tabular}

Fuente: Elaboración propia

Los resultados obtenidos en esta investigación servirán de apoyo para la discusión y conclusiones, donde se destacan las opiniones relevantes sobre el tema de otros investigadores.

\section{Discusión}

Esta investigación muestra que las auditorías son percibidas por las pymes como un proceso que sirve para detectar fraudes y que solamente son utilizadas por las grandes empresas debido a que están obligadas a realizarlas. Asimismo, la confunden con la auditoría fiscal, por lo que manifiestan su temor al respecto.

Asimismo, opinan que las auditorías son costosas, lo que coincide con lo reportado por Hellman (2006) y Sánchez (2015), quienes manifiestan que las empresas demandan mejores servicios que contribuyan al eficiente control de sus recursos y a prevenir riesgos, y no tanto a detectar fraudes. En efecto, las organizaciones que recurren a las auditorías se desaniman porque el precio es un factor que determina la decisión de contratar dichos servicios (Johnson y Lys, 1990; Pitman y Fortin, 2004), en especial cuando no generan los beneficios esperados. A pesar de que existen autores que están a favor de las auditorías y que afirman que aportan beneficios superiores a los costos (Chung y Narasimhan, 2001; Collis, 2010; Collis et al., 2004), las empresas no lo perciben así dado que expresan que los estudios son muy técnicos, y esperan la contribución de soluciones asociadas con la detección de irregularidades.

No obstante, es satisfactorio subrayar que cuando se explica a las pymes la finalidad de la auditoría financiera, acceden de manera voluntaria, siempre que el costo sea asequible. $\mathrm{Al}$ respecto, Carey, Simnett y Tanewski (2000), Senkow et al. (2001), Minnis (2011) y Collis (2012) señalan las retribuciones de una auditoría voluntaria, como puede ser el fácil acceso a un financiamiento bancario, incluso para obtener una tasa de interés más reducida, ya que disminuye el riesgo por la asimetría de la información y el riesgo moral. 


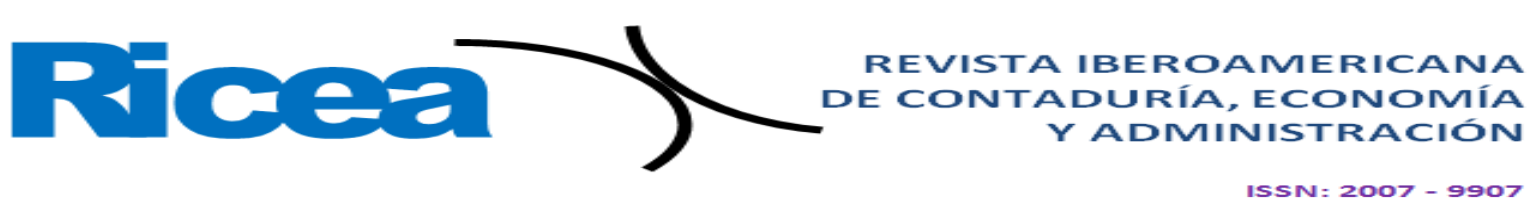

riesgo moral, los cuales repercuten en el establecimiento de las tasas de interés. Al lograr esto, se podrán diseñar de manera habitual estrategias de mejora que combinen variables cualitativas y cuantitativas que impacten en el desarrollo empresarial.

Por otra parte, en cuanto a la aplicación de los métodos de predicción de quiebra empresarial, los principales obstáculos hallados en las pymes tuvieron que ver con la desconfianza y el no contar con los estados financieros, lo que dificultó la evaluación de la situación y ayudar en la predicción de quiebra.

Sería recomendable, por ende, aplicar los métodos antes y durante situaciones imprevistas - como la surgida con la contingencia sanitaria - de manera que se puedan establecer acciones que beneficien a la organización y utilizar la información para solicitar un crédito.

\section{Futuras líneas de investigación}

Los resultados obtenidos sirven para afirmar que la auditoría financiera es aplicable a todas las unidades económicas. Por eso, las universidades pueden contribuir a su aplicación y fomentar una cultura en torno a la elaboración de estados financieros, lo cual impulsaría la permanencia y competitividad de las organizaciones.

Asimismo, se puede indicar que en México existen pocos estudios dedicados a la auditoría financiera en pymes, de ahí que sea necesario efectuar más indagaciones al respecto. Además, se debe trabajar en el desarrollo de nuevos modelos de predicción de quiebra empresarial que ofrezcan certezas más altas, así como continuar las investigaciones sobre los beneficios de la auditoría financiera en pymes y en microempresas. 


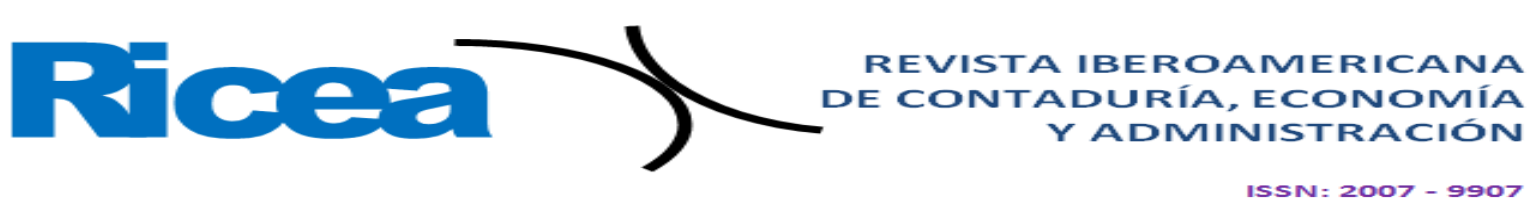

\section{Referencias}

Altman, E. (1968). Financial ratios, discriminant analysis and the prediction of corporate bankruptcy. Journal of Finance, 23(4), 589-609.

Altman, E. and Hotchkiss, E. (2010). Corporate financial distress and bankruptcy: Predict and avoid bankruptcy, analyze and invest in distressed debt ( $3^{\text {th }}$ ed.). John Wiley y Sons.

Altman, E. I. and Sabato, G. (2007). Modelling Credit Risk for SMEs: Evidence from the US Market. Abacus, 43(3), 332-357. Doi: http://dx.doi.org/10.1111/j.14676281.2007.00234.x

Alzate Marín, J. (2008). Cómo medir la quiebra de las empresas en Santander, el modelo logístico: una herramienta para evaluar el riesgo de quiebra. Revista CIFE.

Behr, P. and Güttler, A. (2007). Credit Risk Assessment and Relationship Lending: An Empirical Analysis of German Small and Medium Sized Enterprises. Journal of Small Business Management, 45(2), 194-213. Doi: http://dx.doi.org/10.1111/j.1540627X.2007.00209.x

Bernal, J. (2011). Cómo calcular la posibilidad de quiebra: modelo Z-Score de Altman. Estrategia Financiera, (287), 8-16.

Cámara de Diputados del H. Congreso de la Unión (2021). Código Fiscal de la Federación (CFF). Última reforma publicada en el Diario Oficial de la Federación el 12 de $\begin{array}{llll}\text { noviembre } & \text { de } & 2021 . & \text { Recuperado }\end{array}$ http://www.diputados.gob.mx/LeyesBiblio/pdf/8_110121.pdf

Cámara de Diputados del H. Congreso de la Unión (2021). Ley para el desarrollo de la competitividad de la micro, pequeña y mediana empresa. Última reforma publicada en el Diario Oficial de la Federación DOF, el 13 de agosto de 2019. Recuperado de http://www.diputados.gob.mx/LeyesBiblio/pdf/247_130819.pdf

Carey, P., Simnett, R. and Tanewski, G. (2000). Voluntary demand form internal and external auditing by family businesses. Ear and Hearing, 19, 37-51.

Celaya, R. y López, M. (2004). ¿Cómo determinar su riesgo empresarial? Revista EAN, (52), 68-75. Recuperado de http://www.scielo.org.co/pdf/cenes/v35n62/v35n62a06.pdf

Chernobai, A. and Rachev, S. (2006). Applying Robust Methods to Operational Risk Modeling. Journal of Operational Risk, 1(1), 27-41. Retrieved from https://www.semanticscholar.org/paper/Applying-Robust-Methods-to-OperationalRisk-Chernobai-Rachev/529959eacba71a2c6be5236ab9f35e15ab4e08f0

Chowdhry, B. and Howe, J. T. (1999). Corporate Risk Management for Multinational Corporations: Financial and Operational Hedging Policies. European Finance Review, 


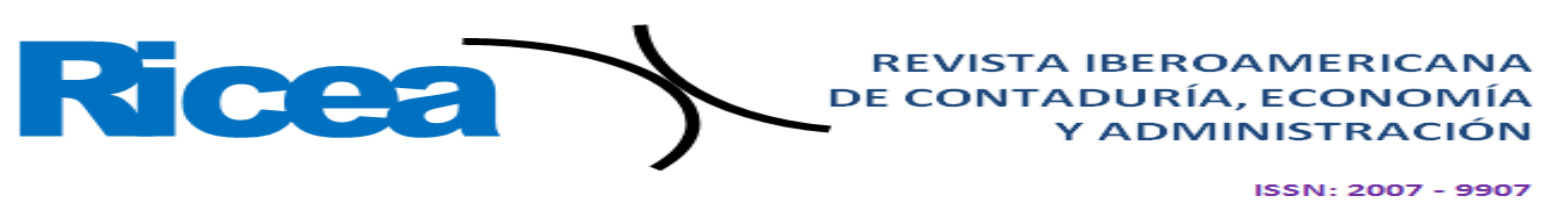

2(2), 229-246. Retrieved from https://ideas.repec.org/a/oup/revfin/v2y1999i2p229246.html

Chung, S. and Narasimhan, R. (2001). Perceived value of mandatory audits of small companies.

Managerial Auditing Journal, 16(3), 120-123. Doi:
https://doi.org/10.1108/02686900110385551

Collis, J. (2008). Directors' views on accounting and auditing requirements for SMEs (project report). London : Department for Business Enterprise \& Regulatory Reform.

Collis, J. (2010). Audit Exemption and the Demand for Voluntary Audit: A Comparative Study of the UK and Denmark. International Journal of Auditing, 14(2), 211-231. Doi: https://doi.org/10.1111/j.1099-1123.2010.00415.x

Collis, J. (2012). Determinants of voluntary audit and voluntary full accounts in micro- and non-micro small companies in the UK. Accounting and Business Research, 42(4), 441468.

Collis, J., Jarvis, R. and Skerratt, L. (2004). The demand for the audit in small companies in the UK. Accounting and Business Research, 34(2), 87-100. Doi: https://doi.org/10.1080/00014788.2004.9729955

Cruz, M. (2004). Operational risk modelling and analys: Theory and practice. London: Incisive Media Investments Limited - Book Risk.

Díaz, J. L. (2011). Diferencia entre las NIA y las NAGA en la contaduría pública en Colombia. Dictamen Libre, (8), 32-38.

Directorio Empresarial (2019). Lista de empresas en Celaya, Guanajuato. Recuperado de https://pymes.org.mx/municipio/celaya-f247.html

Fantazzini, D. and Figini, S. (2008). Default forecasting for small-medium enterprises: does heterogeneity matter? International Journal of Risk Assessment and Management, 11(12), 138-163.

Frachot, A., Moudoulaud, O. and Roncalli, T. (2003). Loss Distribution Approach in Practice. Retrieved from http://www.thierry-roncalli.com/download/lda.pdf

Franco-Ángel, M. y Urbano, D. (2016). Factores determinantes del dinamismo de las pequeñas y medianas empresas en Colombia. Revista de Ciencias Sociales, 22(1), 110-125.

Fulmer, J., Moon, J., James, E., Gavin, T., Erwin, M. and Michael, J. (1984). A bankruptcy classification model for small firms. Journal of Commercial Bank Lending, 25-37.

García, M. A. y Vico, A. (2003). Los escándalos financieros y la auditoría: pérdida y recuperación de la confianza en una profesión en crisis. Generalitat Valenciana: Conselleria d'Economía i Hisenda, (7), 25-48. 


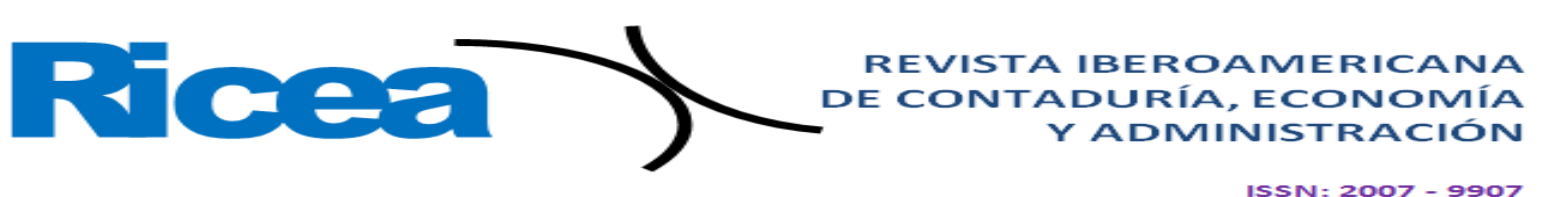

Gillet, R., Hübner, G. and Plunus, S. (2010). Operational Risk and Reputation in the Financial Industry. Journal of Banking y Finance, 34(1), 224-235.

Giner, B. y Gil de Albornoz, B. (2013). Predicción del fracaso empresarial en los sectores de construcción e inmobiliario: modelos generales versus específicos. Universia Business Review, 3(39).

Gordini, N. (2014). A genetic algorithm approach for SMEs bankruptcy prediction: Empirical evidence from Italy. Expert Systems with Applications, 41(14), 6433-6445. Retrieved from https://www.sciencedirect.com/science/article/abs/pii/S0957417414002486

Hellman, N. (2006). Auditor-client interaction and client usefulness: A Swedish case study. International Journal of Auditing, 10(2), 99-124.

Herreros, J. (22 de febrero de 2015). Informes de auditoría más transparentes. Auditoría \& Co. Recuperado de http://auditoria-auditores.com/articulos/articulo-auditoria-informes-deauditoria-mas-transparentes/

Instituto Nacional de Estadística Geografía e Informática (Inegi) (2019). INEGI presenta resultados de la Encuesta Nacional sobre Productividad y Competitividad de las micro, pequeñas y medianas empresas (ENAPROCE). Secretaría de Economía. Recuperado de https://www.inegi.org.mx/contenidos/saladeprensa/boletines/2019/especiales/ENAPR OCE2018.pdf

Jiménez, W. (2013). Uso de herramientas financieras tradicionales y multivariantes (tesis de maestría). México: Universidad de Montemorelos.

Johnson, B. y Lys, T. (1990). The market for audit services: Evidence from voluntary auditor changes. Journal of Accounting and Economics, 12(1-3), 281-308.

Khemais, Z., Nesrine, D. and Mohamed, M. (2016). Credit Scoring and Default Risk Prediction: A Comparative Study between Discriminant Analysis y Logistic Regression. International Journal of Economics and Finance, 8(4), 39.

Knechel, W. R., Niemi, L. y Sundgren, S. (2008). Determinants of auditor choice: Evidence from a small client market. International Journal of Auditing, 12(1), 65-88. Doi: https://doi.org/10.1111/j.1099-1123.2008.00370.x

Kornyliuk, A. (2014). The analysis of the financial risks of domestic agriholdings. The Advanced Science Journal, (11), 65-68.

Kou, G., Xu, Y., Peng, Y., Shen, F., Chen, Y., Chang, K. and Kou, S. (2021). Bankruptcy prediction for SMEs using transactional data and two-stage multiobjective feature selection. Decision $\quad$ Support Systems, $140 . \quad$ Retrieved from https://www.sciencedirect.com/science/article/pii/S0167923620301846

Legault, J. (1987). C.A.-Score, a warning system for small business failures. Bilanas, 29-31. 


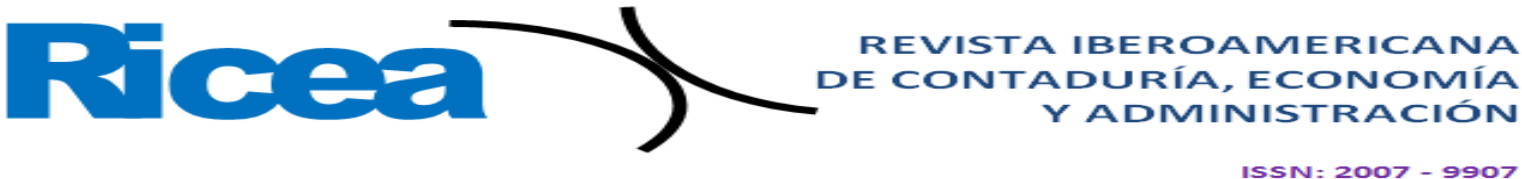

Lozano, E. (2013). Percepción de las mipymes constructoras acerca de los apalancamientos financieros: el estado de Guanajuato como estudio de caso. XVIII Congreso Internacional de Contaduría, Administración e Informática. México, D. F.: UNAM.

Lozano, E. (2014). Alternativas de financiamiento para el desarrollo regional del sector de la construcción en el estado de Guanajuato. En Molina, R. C. (coord.), Emprendimiento y mipymes: nuevo balance y perspectivas (pp. 192-204). Pearson, Celaya, México.

Marshall, C. L. and Marshall, D. C. (2001). Measuring and managing operational risks in financial institutions: tools, techniques, and other resources. New York: J. Wiley, Ed.

Meza, E. (2 de diciembre de 2020). Más de un millón de mipymes han cerrado en México por la pandemia: Inegi. El Economista. Recuperado de https://www.eleconomista.com.mx/empresas/Mas-de-un-millon-de-mipymes-cierrandefinitivamente-por-la-pandemia-INEGI-20201202-0089.html

Minnis, M. (2011). The value of financial statement verification in debt financing: evidence from private U.S. firms. Journal of Accounting Research, 49(2), 457-506.

Módica-Milo, A., Baixauli, J. and Alvarez, S. (2012). Indicator of Financial Health Proposal and its Impact on Probability of Default. Revista International Administración y Finanzas, 5(3), 19-40.

Morales, M. y Pech, J. (2000). Competitividad y estrategia: el enfoque de las competencias esenciales y el enfoque basado en los recursos. Contaduría y Administración, (197), $47-$ 63. Recuperado de http://www.ejournal.unam.mx/rca/rca_index.html

Niemi, L. (2012). Drivers of voluntary audit in Finland: to be or not to be audited? Accounting and Business Review, 42(2), 169-196.

Instituto Mexicano de Contadores Públicos (2019). Normas de Información Financiera (NIF). Recuperado de https://imcp.org.mx/las-normas-informacion-financiera/

Pitman, J. and Fortin, S. (2004). Auditor choice and the cost of debt capital for newly public firms. Journal of Accounting and Economics, 37(1), 113-136.

Restrepo, J., Díaz, J. and Ocampo, J. (2014). Operational risk analysis of industrial small and medium enterprises. Global Journal of Business Research, 8(2), 65-76.

Romero Espinosa, F. (2013). Alcances y limitaciones de los modelos de capacidad predictiva en el análisis del fracaso empresarial. AD-minister, (23), 45-70.

Sánchez, G. (2015). Auditoría de estados financieros (2. ${ }^{a}$ ed.). México, Pearson Educación.

Senkow, D. W., Rennie, M., Rennie, R. D. and Wong, J.W. (2001). The Audit Retention Decision in the Face of Deregulation: Evidence from Large Private Canadian Corporations. Ear and Hearing, 20, 101-113. 


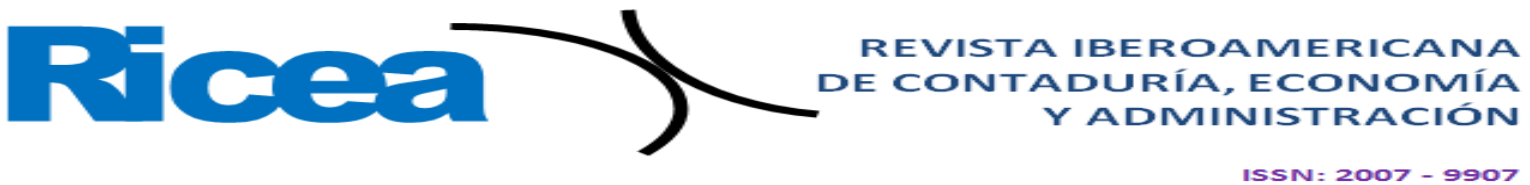

Springate, G. (1978). Predicting the Possibility of Failure in a Canadian Firm: A Discriminant Analysis (doctoral dissertation). Simon Fraser University.

Stevanovski, M., Velkovski, V. y Stevanovska, K. (2013). The relation between the long-term investments and the risk in agro-industrial complex. Journal of Hygienic Engineering and Design, 4, 127-131.

Tobback, E., Bellotti, T., Moeyersoms, J., Stankova, M. and Martens, D. (2017). Bankruptcy prediction for SMEs using relational data. Decision Support Systems, 102, 69-81. Retrieved from https://www.sciencedirect.com/science/article/pii/S0167923617301380?casa_token=m cfieTzFNLcAAAAA:FpLdVBI_VlzXX55URULtpOhjRI3c4rNGSNpphgB8uhDdJQZ X31oJOd1M-c1vISvELSDnoA6qoeL

\section{Anexos}

\section{Cuestionario}

El objetivo de este cuestionario es analizar el concepto que tienen las pymes respecto de la auditoría financiera y sus beneficios, así como de la participación voluntaria en la aplicación de los modelos de predicción de quiebra empresarial. Agradecemos su participación en la aplicación de este cuestionario. La información será utilizada para fines académicos y será tratada de manera confidencial.

Nombre de la unidad económica (opcional)

\section{1.- Antigüedad:}

a) Hasta 2 años, b) más de 2 y hasta 5 años, c) más de 5 y hasta 10 años, d) más de 10 años.

2.- El tamaño de la empresa la considera: (por número de empleados):
a) Micro (0-10),
b) pequeña (11-50),
c) mediana (51-250), d) grande (más de 250).

3.- Giro-actividad principal:

\section{4.- La unidad económica es:}
a) Persona física,
b) Persona moral

5.- ¿Cuál es el grado de estudios del dueño o del gerente general de la unidad económica?
a) Primaria y secundaria
b) Bachillerato
c) Licenciatura
d) Posgrado

6.- ¿Considera que su empresa es familiar? (las acciones son propiedad de la familia y son los que toman las decisiones)

a) Sí, b) No

7.- Cuando escucha el término auditoría, ¿qué impresión le causa?

a) Confianza, b) temor, c) es indiferente, d) hizo algo indebido, e) otro: 
8.- ¿Ha escuchado hablar de la auditoría financiera?

a) Sí, b) No

La auditoría financiera es un proceso de revisión que consiste en la evaluación de la gestión financiera y contable de una empresa para proporcionar estrategias de mejora que apoyen en la permanencia y prevengan la quiebra empresarial hasta por dos años de anticipación.

9.- Ahora que conoce en qué consiste la auditoría financiera, ¿estaría dispuesto(a) a acceder de manera voluntaria?

a) Sí, b) No

10.- ¿Ha participado alguna vez en una auditoría?

a) Sí, b) No.

11.- Si su respuesta es afirmativa, ¿en qué tipo de auditoría?

12.- ¿Piensa que las auditorías financieras son costosas?

a) Sí, b) No

13.- ¿Piensa que las auditorías financieras son solamente aplicables para las grandes empresas?

a) Sí, b) No

\section{Comentarios}

\section{Entrevista para pymes}

Con la finalidad de conocer de manera directa algunos aspectos relevantes tanto favorables como áreas de oportunidad, se le solicita contestar las siguientes preguntas:

1.- ¿Cuáles son las principales fortalezas que presenta la unidad económica? Considere 5 para la más alta y 1 para la más baja. 


\begin{tabular}{|l|l|}
\hline Factores & Consideración \\
\hline a) Situación financiera & \\
\hline b) Acceso a financiamiento & \\
\hline c) Administración de sus bienes & \\
\hline d) Control de inventario & \\
\hline e) Control eficiente de la cartera & \\
\hline f) Posicionamiento en el mercado & \\
\hline g) Situación fiscal & \\
\hline
\end{tabular}

Realizar preguntas con los elementos que se han detectado como fortalezas.

¿Por qué los considera como fortalezas?

¿Qué mejoras se han implementado?

¿Existe otra fortaleza que quisiera mencionar?, etc.

Comentarios adicionales:

2.- ¿Cuáles son las principales debilidades y áreas de oportunidad que presenta la unidad económica? Considere 5 para la más alta y 1 para la más baja.

\begin{tabular}{|l|l|}
\hline Factores & Consideración \\
\hline a) Situación financiera & \\
\hline b) Eficiencia administrativa & \\
\hline c) Financiamiento asequible & \\
\hline d) Cartera vencida & \\
\hline e) Activos fijos obsoletos & \\
\hline f) Tecnología de punta (alta tecnología) & \\
\hline g) Reducción de costos y gastos & \\
\hline h) Competencia nacional e internacional & \\
\hline
\end{tabular}

Realizar preguntas con los elementos que se han detectado como debilidades.

¿Qué obstáculos se han presentado para superar las debilidades mencionadas?

¿Tiene detectadas otras áreas de oportunidad que puede aprovechar?

¿Qué requiere para desarrollar y superar esas áreas de oportunidad?

Comentarios adicionales: 


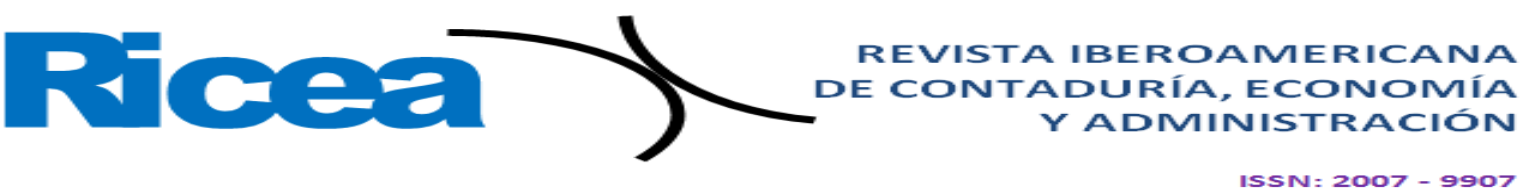

3.- ¿Qué beneficios espera después de participar de manera voluntaria en la aplicación de los modelos de predicción de quiebra empresarial? 